\title{
FUNGSI TARI MANGANJAN DALAM UPACARA TIWAH SUKU DAYAK NGAJU DI KABUPATEN GUNUNG MAS PROVINSI KALIMANTAN TENGAH
}

\author{
Trisna Loli Anjani \\ Jurusan Tari, Fakultas Seni Pertunjukan, Institut Seni Indonesia Yogyakarta \\ Email: trisnaloli16@gmail.com
}

\begin{abstract}
RINGKASAN
Tulisan ini mengupas "Fungsi Tari Manganjan Dalam Upacara Tiwah Dayak Ngaju Kabupaten Gunung Mas Provinsi Kalimantan Tengah". Manganjan adalah tarian yang dilakukan oleh Anak Tiwah untuk berkomunikasi dengan roh leluhur dalam upacara Tiwah. Tiwah dalam suku Dayak Ngaju adalah ritual tertinggi dalam rukun kematian agama Hindu Kaharingan, dengan tujuan untuk mengantarkan arwah ke negeri para arwah. Tari dan semua aspek pendukung yang telah terstruktur dalam upacara Tiwah memiliki peran yang sangat penting. Untuk memecahkan permasalahan penelitian ini digunakan teori struktural fungsionalisme dalam perspektif antropologi dari landasan pemikiran A.R. Radcliffe Brown. Teori ini mengupas tentang struktur dan fungsi dalam masyarakat primitif. Brown menyatakan sebuah kerangka kerja yang menggambarkan konsep-konsep dasar yang berkaitan dengan struktur sosial dari peradaban masyarakat tertentu, di mana berbagai upacara agama dikaitkan dengan mitologi atau dongeng-dongeng suci yang bersangkutan, dan pengaruh dan efeknya terhadap struktur hubungan antara warga dalam suatu komunitas. Hasil penelitian memperlihatkan bahwa Tari Manganjan dalam upacara Tiwah memiliki unsur-unsur seperti, pelaku, gerak, iringan musik, syair, tempat pertunjukan, busana, properti, pola lantai, perlengkapan upacara, dan sebagainya. Unsur-unsur tersebut saling berhubungan, berelasi antara satu dengan yang lainnya sehingga menjadi sistem yang kompleks dan terstruktur. Unsur-unsur tersebut yang saling berhubungan satu sama lain dalam upacara Tiwah, berfungsi, beroperasi dan bergerak dalam satu kesatuan.
\end{abstract}

Kata-Kata Kunci: tari mangajan, upacara tiwah, dayak ngaju

\begin{abstract}
This paper explores "The Function of Manganjan Dance in the Tiwah Dayak Ngaju Ceremony of Gunung Mas Regency, Central Kalimantan Province". Manganjan is a dance performed by Anak Tiwah to communicate with ancestral spirits in a Tiwah ceremony. Tiwah in the Dayak Ngaju tribe is the highest ritual in the pillars of the death of the Hindu Kaharingan religion, with the aim of delivering spirits to the land of the spirits. Dance and all supporting aspects that have been structured in the Tiwah ceremony have a very important role.

To solve this research problem, structural theory functionalism is used in the anthropological perspective from A.R. Radcliffe Brown. This theory explores the structure and function in primitive societies. Brown states a framework that describes the basic concepts relating to the social structure of a particular civilization, in which various religious ceremonies are linked to the mythology or sacred tales in question, and their influence and effect on the structure of the relationship between citizens in a community.
\end{abstract}


The results showed that the Manganjan Dance in the Tiwah ceremony had elements such as actors, movements, musical accompaniment, poetry, venues, clothing, property, floor patterns, ceremonial equipment, and so on. These elements are interconnected, related to one another so that it becomes a complex and structured system. These elements which are interconnected with each other in the Tiwah ceremony, function, operate and move in one unit.

Key words: mangajan dance, tiwah ceremony, ngaju dayak

\section{PENDAHULUAN}

Kata Dayak adalah sebutan yang umum di Kalimantan. Dayak adalah satu perkataan untuk menyatakan suku-suku yang tidak beragama Islam dan mendiami pedalaman Kalimantan, dan istilah Dayak ini diberikan oleh orang Melayu pesisir Kalimantan yang berarti orang Gunung (Nila Riwut, 2003:101).

Penduduk utama Kalimantan Tengah adalah suku Dayak yang menggunakan bahasa Dayak Ngaju. Penduduk di Kalimantan Tengah masih menganut agama lama yang ada sampai sekarang yaitu agama Kaharingan. Kaharingan adalah kepercayaan atau agama asli suku Dayak Kalimantan, ketika agama-agama besar belum memasuki Kalimantan. Di dalam agama Kaharingan dikenal upacara Tiwah.

"Tiwah" adalah ritual tertinggi dalam rukun kematian agama Hindu Kaharingan. Upacara ini bertujuan untuk menghantarkan arwah ke negeri para arwah. Upacara kematian biasanya digelar atas seseorang yang telah meninggal dan dikubur sekian lama hingga yang tersisa dari jenazahnya diperkirakan hanya tinggal tulangnya saja.
Upacara Tiwah diawali dengan diadakannya musyawarah di antara para Tetuha Kampung yang inti pembicaraannya adalah permasalahan Tiwah yang akan segera dilaksanakan. Hal-hal yang dibahas antara lain, siapa saja yang berminat ikut serta meniwahkan kaum keluarganya, berapa jumlah jiwa yang akan di-Tiwah-kan dari setiap keluarga yang telah bersepakat untuk ikut ambil bagian dalam upacara Tiwah, dan akhirnya menentukan seorang wakil dari beberapa keluarga yang telah menyatakan diri ikut ambil bagian dalam pesta Tiwah yang disebut Bakas Tiwah yang tugasnya bertanggung jawab dalam segala hal. Sejak mengawali musyawarah hingga akhir dari seluruh acara dalam upacara Tiwah dimufakati dengan dasar bekerja secara bersama-sama serta saling tolong menolong. Apabila kesepakatan sudah diputuskan, barulah menanyakan dan menentukan binatang apa yang akan dikurbankan oleh tiap-tiap keluarga yang telah menyatakan ikut ambil bagian dalam upacara Tiwah, juga tidak lupa membahas berapa besar biaya yang sanggup dikeluarkan 
dari setiap keluarga yang berminat turut serta meniwahkan keluargannya, dan terakhir memusyawarahkan siapa yang nantinya dimohonkan bantuan untuk mengantar jiwa, apakah Mahanteran atau Balian.

Penentuan Bakas Tiwah selalu dipilih seorang Kaharingan yang dipandang ahli dalam bidangnya sesuai dengan perintah Tinggang Rangga Tantaulang Bulau (Datuk Para Dewa dan Manusia), yang mana bila dalam pelaksanaan pesta terjadi kekeliruan ataupun kurang ada kesungguhan maka akan berakibat fatal bagi Bakas Tiwah, yang antara lain dapat mengakibatkan:

1. Pali akan pambelum itah harian (mempunyai dampak kurang baik dalam kehidupan masa mendatang).

2. Tau pamperesen itah limbah gawie toh (mempunyai dampak kurang baik bagi kesehatan)

3. Indu kakicas, pambelum itah andau harian (bisa mendapat kutukan di masa mendatang).(Tjilik Riwut, 2007:385-386) Pada tanggal dan hari yang telah disepakati, para ahli waris yang akan Tiwah berkumpul dalam suatu tempat yang disebut Balai Pangun Jandau (balai yang didirikan sehari) dan setiap ketua ahli waris datang membawa ayam yang jumlahnya sesuai dengan jumlah jiwa yang akan di-Tiwah-kan. Bakas Tiwah membunuh seekor babi. Pada saat mendirikan Balai Pangun Jandau, Bakas
Tiwah menyediakan Pasar Sababulu sebagai tanda perkakas Tiwah dan dawen silar yaitu daun silar sebagai palas bukit.

Hari kedua, sebelum seekor babi dibunuh, disaat subuh, sebelum suara bunyibunyian diperdengarkan, juga sebelum diadakan saki palas, di sekeliling sangkaraya didirikan bambu kuning dan lamiang (tamiang palingkau), dan memasang kain-kain berwarna kuning serta bendera Panjang Ngamban Kabanteran Bulan Rarusir Ambu Ngekah Lumpung Matanandau (bendera panjang warna kuning dengan gambar bulan di tengah-tengah dan disinari cahaya matahari dari atas). Peserta pesta mengenakan Penyang Gawing Haramaung baju kalambi barun rakauan salingkat sangkarut, ewah bumbun, memakai destar lawung sampulai dare nucung dandan tingang yang diikat dohong sanaman mantikei pada leher serta diikatkan juga di lamiang pating pilang santagi raja, kemudian menggunakan kain (benang ranggam malahui) lalu bendera dinaikkan ke atas sangkaraya. Setelah itu babi dibunuh dan darahnya digunakan untuk manyaki-mamalas serta mendirikan sangkaraya sandung rahung (tempat menyimpan tulang belulang) dan diletakkan di depan rumah Bakas Tiwah. (Tjilik Riwut, 2007: 386-387)

Dihari kedua inilah mulai dibunyikan bunyi-bunyian khusus Tiwah yaitu: gong, gendang, kangkanung, gandang-garantung, 


\section{JOGED}

ISSN: $1858-3989$

katambung, dan tarai. Kesemua alat bunyibunyian ini juga disaki dengan darah babi yang telah dipotong pada hari kedua ini.

Tawur juga diadakan pada hari kedua yang intinya menghubungi dan memberi tahu Salumpuk Liau (roh yang akan ditiwahkan) dan diharapkan Salumpuk Liau memohon izin kepada Sangiang, Jata, Naga Galang Petak, Nyaring, Pampahilap, juga diharapkan Salumpuk Liau memberitahukan kepada Sangumang, Sangkanak, Kambe Hai, bintang bulan, patendu, jakarana, matanandau, bahwa upacara Tiwah akan segera diadakan.

Untuk menghormati Sangiang yang berperan menghantarkan jiwa yang meninggal ke alam yang baka, semua yang hadir turut menari dan Manganjan, di mana hal tersebut dilaksanakan pada hari ke 3, tarian dimulai oleh 3 orang, hari ke 4 oleh 4 orang, hari ke 5 oleh 5 orang, hari ke 6 oleh 6 orang, hari ke 7 oleh 7 orang. Pada hari 3 merupakan puncak acara Tiwah yang mana semua bunyi-bunyian dibunyikan, suasana kegembiraan terdengar di sana sini dan beras kuning mulai ditaburkan dengan arah ke atas. Saat inilah keluarga terdekat dari jiwa/roh yang sedang di-Tiwahkan turun ke tanah dengan membawa air kunir yang kemudian diusapkan pada kaki dan tangan orang yang sedang menari, serta diberikan ketan, nasi, kaki ayam, dan lemak babi, kemudian kepala orang yang sedang menari dituangi minyak dan disuguhi
FUNGSI TARI MANGANJAN DALAM UPACARA TIWAH SUKU DAYAK NGAJU DI KABUPATEN GUNUNG MAS PROVINSI KALIMANTAN TENGAH

Tuak/Baram/Arak. Semua ini mempunyai maksud agar jiwa/roh yang sedang di-Tiwahkan turut bergembira bersama-sama sanak keluarga dan handai taulan karena pada hari ini jiwa/roh yang di-Tiwah-kan (Tjilik Riwut, 2007:387) dapat berkumpul kembali bahkan dapat berpesta bersama-sama handai taulan dan sanak keluarga tetapi dalam bentuk tidak kelihatan. Selesai acara ini barulah disuguhkan sirih dan rokok.

Setelah acara menari selesai, diadakan upacara pembunuhan babi/kerbau/sapi yang sebelumnya telah diikat di Sangkaraya. Darah binatang yang dibunuh ditaruh di suatu tempat yang disebut Sangku yang nantinya akan digunakan sebagai pembasuh dari hal-hal yang kotor. Diyakini bahwa darah yang ada di dalam sangku adalah darah Rawing Tempun Telon yeng telah diberkati oleh Ranying (Allah). Darah di Sangku digunakan untuk manyaki semua batu-batu Pangantoho, minyak sangkalemu, minyak tatamba ramu, mandau, penyang, karuhei tatau, serta peralatan yang digunakan dalam peralatan Tiwah. Setelah darah digunakan untuk menyaki, sisanya dicampur dengan beras kemudian dilempar dengan arah ke atas, serta ditaburkan ke segala penjuru dengan maksud agar jiwa yang ada di dalam beras dapat bersatu dengan masyarakat yang sedang mengadakan upacara Tiwah. Harapannya agar semua yang hadir diberikan keselamatan, dijauhkan dari seagala bahaya dan 
penyakit, diberikan umur panjang, serta hidup tenteram dan damai sebagaimana dinginnya darah binatang yang dijadikan kurban. Masyarakat mempercayai, segala badan yang dingin akan jauh dari segala rintangan hidup.

Di dekat batang tempat pesta, didirikan tiang panjang yang dinamakan tiang mandera sebagai tanda bagi pendatang bahwa di kampung tersebut telah diadakan upacara Tiwah yang berarti mereka tidak boleh masuk ke kampung itu bila tidak memenuhi persyaratan yang ada. Bagi pendatang yang tidak mematuhi peraturan dan persyaratan tersebut, dapat mengakibatkan ia akan ditangkap dan kemudian dibunuh pada saat itu juga inyarah (diserahkan) di sangkaraya dan kepalanya dipotong untuk dijadikan pengantar atau budak bagi roh yang di-Tiwah-kan, (namun hal ini hanya terjadi di masa yang telah lalu).( Tjilik Riwut, 2007:388).

Upacara selanjutnya duduklah seorang yang bertugas manawur di atas gong seraya manangking dohong nucung dandang tingang. Pada hari ke 5 didirikan pantar tabalien. Pantar tabalien adalah tiang kayu yang berbentuk menjulang tinggi dan bisa mencapai 50-60 meter sebagai jalan bagi jiwa yang akan masuk ke alam baka. Sejak saat itu sapi, kerbau, mulai diikat di sapundu siang dan malam, disaat itu sekali lagi sandung dan pambak tempat menyimpan tulang belulang disaki/dipalas dengan darah babi/kerbau, dan selama tujuh hari sandung tersebut dipali yang berarti lalu lintas dalam kampung kena pali dan yang terkena pali harus membayar denda. Tiap-tiap hari selama diadakannya upacara Tiwah, dipotong babi dan masyarakat yang menghadiri upacara Tiwah, akan manganjan (menari) mengelilingi binatang yang akan dikurbankan sebagai penghormatan kepada arwah yang diTiwah-kan.

Setelah itu dimulai mengumpulkan perkakas untuk memasak dalam bambu dan dibungkus dengan daun itik. Disediakan juga baram/tuak/arak dan balian/mahanteran mengawali pengantaran arwah ke alam baka. Apabila Basir telah datang, maka handepang telon (wakil telon) akan mahanteran dan mengantar salumpuk liau, panawur dan masyarakat yang hadir dalam upacara Tiwah telah siap di balai. Basir mengenakan pakaian yang indah yang sebelumya telah disiapkan oleh ahli waris arwah-arwah yang di-Tiwahkan. Kemudian basir dan balian duduk di atas katil garing dan siap memegang sambang/katambung. Cara duduk telah ditentukan yaitu basir duduk di sebelah tengah yang diapit oleh 2 orang dan ada 4 orang yang di sebelah belakang (Tjilik Riwut, 2007:389). Upah yang akan diterima basir ditentukan sebelum balian dimulai. Saat itu penawur memulai tugasnya menurut tatulak balian yang artinya membuang sial, membuang segala 


\section{JOGED}

ISSN: $1858-3989$

bencana yang akan mengacaukan upacara Tiwah.

Acara dilanjutkan dengan penikaman dengan menggunakan tombak/lunju pada binatang kurban yang dilakukan oleh para ahli waris liau dengan cara:

1. Bakas Tiwah menikam lambung sebelah kanan, bekas tikamannya dinamakan kempas bunuhan.

2. Salah seorang (perempuan) yang mewakili ahli waris liau juga menikam tombak/lunju pada binatang kurban dan bekas tikamannya dinamakan pekas bunuhan.

3. Salah seorang wakil masyarakat yang hadir dalam upacara juga menikam binatang kurban, bekas tikamannya dinamakan timbalan bunuhan atau boleh juga dilakukan dengan urutan: tikaman pertama dilakukan oleh Bakas Tiwah, tikaman kedua oleh pemotong pantan dan tikaman ketiga dilakukan oleh salah seorang tetua kampung.

Setelah itu diadakan Kanjan Hatue yaitu tari kanjan yang hanya dibawakan oleh lakilaki, kemudian diadakan acara masak memasak menyiapkan makanan yang diletakkan dalam banama yang nantinya akan dibawakan oleh telon ke alam baka. Juga menyiapkan makanan bagi para dewa, sangiang, nyaring, pampabilep, sangkanak, dan kambe. Makanan juga disediakan untuk buat burung dahiang seperti burung bakutok, papau, antang (Tjilik Riwut, 2007: 391).
FUNGSI TARI MANGANJAN DALAM UPACARA TIWAH SUKU DAYAK NGAJU DI KABUPATEN GUNUNG MAS PROVINSI KALIMANTAN TENGAH

Makanan yang telah disiapkan dilemparkan ke arah bawah bagi arwah yang sedang diantarkan ke alam baka, dilempar arah ke kanan bagi raja untung dan arah ke kiri bagi dewa-dewa, arah belakang bagi raja sial. Kemudian diulangi lagi, arah sebelah belakang ditujukan kepada sangumang dan sangkanak sebelah atas untuk bulan, binatang, matahari, patendu, kilat, nyahu. Setelah acara ini selesai maka masyarakat yang hadir dalam upacara kembali berkumpul.

Tibalah saatnya tulang-belulang orang yang arwahnya di-Tiwah-kan digali, kemudian tulang-tulang yang ditemukan diletakkan di dalam peti dan pada hari yang sama dimasukkan ke dalam tambak/pambak/sandung dan didirikan pantar serta diadakan suatu upacara bajamuk dan hapuar.

Bila semua urutan upacara sudah dilaksanakan maka salumpuk liau sudah sampai ke negeri yang dituju. Untuk memberikan kesempatan beristirahat bagi balian dan basir, diberikan waktu 1 hari. Setelah itu selama 3 hari berturut-turut diadakan pesta dengan memotong babi dan acara minum tuak/baram beramai-ramai. Hari kedua pada rangkaian 3 hari upacara setelah penggalian tulang, diadakan balian sebagai penghormatan dan ucapan selamat jalan kepada para tamu serta memohon kepada ranying tempon telon untuk selalu memberikan perlindungan. Pada hari yang sama dilakukan juga acara balaku untung 
yaitu memohon rejeki kepada ranying di bukit tunjung nyahu dengan pertolongan rawing tempon telon. Kemudian dilanjutkan dengan acara pemberian tanda mata sebagai hadiah dan ucapan terima kasih kepada balian, mahanteran, yang telah membantu sebagai perantara dalam pelaksanaan upacara Tiwah mengantarkan nenek moyang maupun kaum kerabat ke alam baka. Dihari terakhir, masyarakat yang menghadiri upacara Tiwah berkumpul untuk membayar dan mengantar pulang ke rumah di kampung masing-masing para balian, mahanteran, dan panawur yang telah berjasa sebagai perantara dalam mengantar salumpuk liau ke negeri yang baka (Tjilik Riwut, 2007:392-393). Dengan selesainya upacara Tiwah, keluarga terdekat/ahli waris arwah yang di-Tiwah-kan merasa lega karena telah melaksanakan tugas dan kewajiban, juga sebagai tanda bakti bagi mereka yang telah mendahului pulang ke alam baka.

Pada masyarakat primitf, ritual keagamaan umumnya masih terkait erat dengan seni pertunjukan, dan tari hadir di dalamnya. Sejarah peradaban manusia menunjukkan jejak aktivitas manusia yang berkaitan dengan ritual (Yanti Heriyawati, 2016:1). Umat Hindu Kaharingan percaya bahwa ajaran agama akan memberikan jalan untuk keselamatan manusia karena cinta kasih Ranying Hatala Langit (Tuhan) kepada umatnya. Ranying Hatala
Langit (Tuhan) disebut Maha Bijaksana, Maha Pengasih, Maha Segalanya, karena Tuhanlah yang memberi nafas kehidupan kepada kita dan karena cinta kasih-Nya kita kembali pada-Nya, melalui upacara Tiwah.

Upacara Tiwah dan tari Manganjan adalah dua hal yang tidak dapat dipisahkan. Dalam upacara Tiwah bentuk seni pertunjukan yaitu tari, musik, syair, properti, kostum dan tempat pertunjukan menjadi satu kesatuan. Tari Manganjan adalah tari ritual yang dilakukan oleh masyarakat suku Dayak di Kalimantan Tengah, yang dibawakan oleh laki-laki dan perempuan pada saat upacara Tiwah (menghantarkan arwah nenek moyang ke surga). Para penari menari sambil mengitari/mengelilingi binatang kurban (kerbau/sapi/ babi) yang diikat pada suatu tiang sebelum dan sesudah kerbau itu dibunuh dengan cara ditombak oleh para anggota keluarga yang di-Tiwah-kan. Tarian ini juga dilakukan oleh suku Dayak Klementen, Katingan, dan Kahayan. Dalam tarian ini busana yang digunakan para penari memakai baju keseharian, yaitu baju kaos dan celana yang sopan dengan ditambah properti bahalai (jarik) yang digunakan oleh penari perempuan sedangkan untuk penari laki-laki menggunakan properti mandau (senjata khas suku Dayak). 


\section{JOGED}

ISSN: $1858-3989$

II. PEMBAHASAN

A. Fungsi Tari Mangajan dalam

\section{Upacara Tiwah}

Fungsionalisme-Struktural RadcliffeBrown, adalah teori yang menggagaskan mengenai sebuah kerangka kerja yang menggambarkan konsep-konsep dasar yang berkaitan dengan struktur sosial dari peradaban masyarakat tertentu, di mana berbagai upacara agama dikaitkan dengan mitologi atau dongeng-dongeng suci yang bersangkutan, dan di mana pengaruh dan efeknya terhadap struktur hubungan antara warga dalam suatu komunitas. Brown juga menyarankan untuk memakai istilah "fungsi sosial" untuk menyatakan efek dari suatu keyakinan, adat, atau pranata kepada solidaritas sosial dalam masyarakat tersebut. Sehingga fungsi di sini juga dipahami sebagai suatu bagian aktivitas yang melakukan bagian aktivitasnya secara keseluruhan sebagai sebuah sistem, di mana dalam struktur dan peran memiliki fungsi masing-masing (A.R Radcliffe Brown, 1980:210).

Penelitian fungsi tari Manganjan dalam upacara Tiwah di kabupaten Gunung Mas menggunakan landasan pemikiran Brown yang mengupas struktur dan fungsi dalam masyarakat primitif. Konsep fungsi inipun menganalogikan kehidupan manusia dengan organ tubuh manusia, di mana setiap organ tubuh memiliki aktivitas dan fungsi masing-
FUNGSI TARI MANGANJAN DALAM UPACARA TIWAH SUKU DAYAK NGAJU DI KABUPATEN GUNUNG MAS PROVINSI KALIMANTAN TENGAH

masing. Pertunjukan tari tidak terlepas dari aspek gerak tari, ruang waktu, pendukung, properti, dan rias busana menjadi aspek yang saling terkait satu dengan yang lainnya saling berelasi sehingga dapat memecahkan fungsi Tari Manganjan dalam ritual upacara Tiwah.

\section{B. Struktur Tari Manganjan}

\section{Dalam Upacara Tiwah}

1. Relasi Gerak Tari Mangajan dalam Upacara Tiwah

Pada hakikatnya tari merupakan susunan gerak yang telah mengalami proses penggarapan, gerak merupakan bagian yang hakiki dalam kehidupan (Y. Sumandiyo Hadi, 2012:10). Gerak Manganjan dalam upcara Tiwah, mengacu pada gerak berjalan dan membentang tangan. Gerakan ini pun lebih didominasi pada bagian tangan dan kaki. Bentuk gerak Manganjan mengekspresikan seseorang yang sedang dalam perjalanan. Perjalanan tersebut bukanlah perjalanan yang dilakukan oleh manusia biasa, melainkan perjalanan yang dilakukan oleh roh leluhur arwah yang sudah mati yang telah diTiwahkan.

Gerak tersebut memiliki makna: 1. manduan berkat (pengambilan energi spiritual sebagai kekuatan melepas roh) 2. malapas pali (penyerahan roh ke surga), 3. Mangambali akan biti (terlepasnya pantangan yang disebabkan oleh kematian). Gerak tari Manganjan memiliki gerak maknawi, meskipun gerak Manganjan terlihat sederhana namun gerak 
tersebut mempunyai makna dan relasi terhadap upacara Tiwah.

Tujuan dari manganjan dalam upacara Tiwah, yaitu meminta perlindungan agar upacara yang dilaksanakan dapat berjalan dengan lancar dan terhindar dari gangguangangguan lainnya.

Gerak berjalan dalam Manganjan berfungsi untuk memberitahukan kepada arwah bahwa mereka sedang melakukan upacara Tiwah. Gerak membentangkan tangan berfungsi menyerahkan arwah yang ditiwahkan ke surga.

2. Relasi Iringan Musik dan Syair pada Upacara Tiwah

Manganjan dalam gerakannya diiringi dengan melantunkan syair oleh penari dan tabuhan alat musik kangkanong, gong, gandang, dan tarai. Alat musik ini dimainkan oleh lima orang laki-laki yang disebut Tukang Mantu. Tabuhan alat musik ini mengiringi gerakan Anak Tiwah hingga upacara tersebut selesai. Dalam upacara Tiwah musik yang mengiringi monoton dan diulang-ulang, dari awal hingga akhir. Musik yang mengiringi memiliki tempo yang sama, tetapi dalam pelaksanaan musik pengiring yang monoton dapat menimbulkan kesan magis dan memberikan makna sebagai kekuatan untuk memanggil arwah.

Langkah kaki yang dilakukan anak Tiwah dipengaruhi oleh tempo tabuhan alat musik yang dimainkan. Syair yang dilantunkan oleh anak Tiwah yaitu:

\section{Ololololololololo o hui}

Maksud dari syair memiliki tujuan untuk meminta kepada Tuhan yang maha pencipta agar pekerjaan mereka aman, damai dan tentram, dan para arwah tersebut bisa sampai ke surga.

Iringan musik yang dimainkan oleh Tukang Mantu, selain berfungsi sebagai pengiring, juga memiliki peran penting dalam upacara Tiwah. Jika tidak ada musik tidak akan ada Manganjan dan upacara tidak bisa dilaksanakan. Hal ini dikarenakan iringan musik yang berfungsi untuk membantu langkah kaki anak Tiwah untuk menari meminta perlindungan agar acara dapat terselenggara dengan lancar. Oleh karena itu tidak sembarang orang dapat menjadi Tukang Pantu.

3. Relasi Properti Manganjan pada Upacara Tiwah

Dalam upacara Tiwah properti yang digunakan pada saat Manganjan yaitu selendang dan Mandau. Selendang memilki makna keluhuran, keagungan, mengayomi, yang memiliki fungsi untuk membedakan penari perempuan dan laki-laki, selain itu juga memiliki fungsi untuk menggendong bayi.

Mandau sebagai senjata untuk melindungi diri dari binatang buas, dan musuh. Mandau juga memiliki makna kagagahan, 


\section{JOGED}

ISSN: $1858-3989$

kesatria, penjaga, kedewasaan dan tanggung jawab.

4. Relasi Pola Lantai Manganjan pada Upacara Tiwah

Dalam Manganjan anak Tiwah menari membentuk pola lantai yang selalu melingkar, hal ini dikarenakan gerakan tersebut mengelilingi Sangkaraya. Gerakan melingkar dan diulang secara terus-menerus memiliki sifat sakral dan menyimbolkan sebuah keutuhan yang tidak dapat dipisahkan. Fungsi pola lantai melingkar yaitu sebagai interaksi antara anak Tiwah dan arwah yang di-Tiwah-kan.

\section{Relasi Tempat Pelaksanaan}

\section{Manganjan pada Upacara Tiwah}

Halaman rumah berfungsi sebagai tempat (selama) berlangsungnya pelaksanaan upacara Tiwah tersebut dilaksanakan. Selain itu halaman rumah tersebut juga mempunyai fungsi yang lain (sebelum, selama pelaksanaan dan setelah upacara Tiwah berlangsung), yaitu sebagai apotik hidup.

\section{Relasi Nilai Tari Manganjan}

\section{Dalam Upacara Tiwah}

1. Nilai Ritual

Upacara Tiwah adalah upacara yang dilakukan oleh Agama Kaharingan (Hindu). Dalam upacara ini menggunakan aspek gerak tari, musik, kostum dan properti selain perlengkapan di dalam pelaksanaan.

Menurut Brown, kepercayaan budaya primitf bukanlah dari segi psikologi manusia,
FUNGSI TARI MANGANJAN DALAM UPACARA TIWAH SUKU DAYAK NGAJU DI KABUPATEN GUNUNG MAS PROVINSI KALIMANTAN TENGAH

melainkan mengenai hubungan antara upacara dengan nilai-nilai yang terkandung di dalamnya dengan melakukan kepercayaan lama hingga saat ini (A.R Radcliffe Brown, 1980:170). Seperti upacara Tiwah memiliki nilai-nilai yang terdapat dalam upacara ritual yang masih dilaksanakan hingga saat ini. Dalam hal ini tari digunakan oleh sekelompok manusia sebagai ekspresi komunal, di mana tari sejak zaman pra sejarah telah digunakan oleh kelompokkelompok suku sebagai media upacara ritual yang berhubungan dengan upacara meminta hujan, permohonan meminta kesuburan tanaman, serta pemujaan-pemujaan kepada roh leluhur (Sumaryono, 2016:10)

Upacara Tiwah termasuk dalam adat yang dipercaya dan dijalankan oleh masyarakat suku Dayak Ngaju untuk mengantarkan arwah nenek moyang ke alam surga dengan menyelenggarakan upacara Tiwah. Masyarakat mempercayai adanya kehidupan arwah yang diTiwah-kan akan sampai ke surga dan melanjutkan kehidupannya di alam kedua. Tari Manganjan sebagai media komunikasi kepada roh leluhur dengan menggunakan gerak, syair, musik, dan properti.

\section{Nilai Sosial}

Masyarakat suku Dayak Ngaju dikenal ramah serta memiliki nilai kebersamaan. Sifatsifat kekeluargaan orang Dayak Ngaju sangat tinggi, hal itu dapat dilihat dari kebersamaan mereka dalam membuat suatu kegiatan yang 
saling bergotong-royong. Orang Dayak Ngaju adalah orang yang beradat, dapat dilihat dalam kehidupan mereka sehari-hari memiliki tatakrama. Dalam hal berbicara dengan orang yang lebih tua umurnya, mereka akan berbicara dengan sopan.

Nilai kekerabatan yang kuat dalam suku Dayak Ngaju juga dilihat pada saat pemilihan Tukang Balian untuk menjadi pemimpin dalam upacara Tiwah. Dalam menentukan sesuatu masyarakat suku Dayak Ngaju sangat mengutamakan musyawarah dan mufakat. Musyawarah dan mufakat merupakan dasar kebersamaan bagi masyarakat suku Dayak Ngaju. Selain itu masyarakat Dayak Ngaju juga memiliki tingkat solidaritas yang tinggi, hal ini dapat dilihat apabila diselenggarakan upacara Tiwah, maka dari keluarga yang lain atau dari kampung yang lain, akan membantu seperti membantu membeli hewan kurban. Sebaliknya begitu keluarga yang sudah melaksanakan upacara Tiwah akan membayar apa yang sudah dibantu dari keluarga tersebut, dengan dilaksanakan upacara Tiwah dapat dilihat nilai kekerabatan dan nilai kebersamaan antara masyarakat suku Dayak Ngaju.

\section{Nilai Estetis}

Nilai estetis upacara Tiwah terlihat dari kesederhanaannya yang terwujud dari pola gerak dan iringan yang cenderung monoton. Akan tetapi kesederhanaan ini memunculkan unsur magis dari sebuah pertunjukan, terlebih pada saat anak Tiwah menari sambil melantunkan syair sebagai tanda pemanggilan roh leluhur menambah nilai estetis dalam tari Manganjan. Pementasan tari Manganjan yang tampak sederhana memiliki nilai dan makna yang tinggi. Keindahan suatu tari bukan dilihat dari penarinya yang melakukan gerakan yang lemah gemulai, tetapi dilihat dari bentuk tari yang mempesona yang memiliki nilai dan makna tertentu (Y. Sumandiyo Hadi, 2005:14).

Upacara Tiwah memiliki perlengkapan yang pembuatannya bisa sangat rumit serta memiliki makna dan berfungsi sebagai tempat pemyimpanan hewan kurban dan penyimpanan alat musik.

\section{PENUTUP}

Berdasarkan rumusan masalah penelitian, maka dapat disimpulkan bahwa tari Manganjan adalah tari ritual yang menjadi puncak acara dalam upacara Tiwah. Tari Manganjan merupakan tari sakral yang dipercaya oleh agama Kaharingan (Hindu) dan tidak dapat dipisah dari upacara Tiwah. Tari Manganjan adalah aktivitas yang dilakukan oleh peserta upacara Tiwah dengan media gerak sebagai cara untuk berkomunikasi kepada roh leluhur. Upacara Tiwah dan tari Manganjan merupakan satu kesatuan yang tak terpisahkan.

Pendekatan struktural fungsionalisme A.R Radcliffe Brown yang melihat bahwa struktur tidak terlepas dari fungsinya, maka 


\section{JOGED}

ISSN: $1858-3989$

struktur tari Manganjan dianalisis guna mengupas fungsinya. Upacara Tiwah memiliki struktur dalam pelaksanaannya, di dalam upacara terdapat juga tari Manganjan sebagai puncak acara dari pada upacara ini yang juga memiliki struktur. Semua unsur-unsur yang terdapat dalam upacara Tiwah berperan penting dan memiliki fungsi masing-masing. Untuk melihat fungsi tari Manganjan dalam upacara Tiwah, yaitu dengan melihat sistem relasi dari unsur-unsur tersebut. Unsur-unsur yang saling berelasi, berkaitan dan berhubungan dengan upacara Tiwah mampu mengantarkan arwah roh leluhur ke alam surga. Upacara ini akan selalu dilaksanakan oleh setiap keluarga untuk meniwah-kan kerabatnya.

Fungsi yang diperoleh dari Tari Manganjan dalam upacara Tiwah berelasi dengan nilai ritual pada suku Dayak Ngaju di Kabupaten Gunung Mas, karena melatarbelakangi sebuah upacara Tiwah dilaksanakan dari masyarakat penganutnya itu sendiri. Masyarakat suku Dayak Ngaju tidak meninggalkan adat lawas mereka untuk mengantarkan arwah roh leluhur melalui upacara Tiwah. Tari Manganjan dalam upacara Tiwah juga berelasi dengan nilai sosial, dilihat dengan solidaritas masyarakat suku Dayak Ngaju yang tinggi dalam membantu pelaksanaan upacara Tiwah, serta berelasi dengan nilai estetika yang dapat dilihat dari unsur-unsur didalam upacara Tiwah yang
FUNGSI TARI MANGANJAN DALAM UPACARA TIWAH SUKU DAYAK NGAJU DI KABUPATEN GUNUNG MAS PROVINSI KALIMANTAN TENGAH

sederhana, monoton, dan unik menimbulkan kesan kesakralan dan magis.

\section{DAFTAR SUMBER ACUAN}

Brown, A.R Radcliffe. 1980. Struktur Dan Fungsi Dalam Masyarakat Primitf. Kuala Lumpur: Dewan Bahasa dan Pustaka.

Hadi, Y. Sumandiyo. 2012. Koreografi Teknik-Bentuk-Isi. Yogyakarta: Cipta Media

Heriyawati, Yanti, 2016, Seni Pertunjukan Dan Ritual, Yogyakarta: Ombak

Riwut, Nila 2003. Maneser Panatau Tatu

Hiang. Yogyakarta: Pusakalima.

Riwut, Tjilik. 2007. Kalimantan Membangun Alam dan Kebudayaan. Yogyakarta: NR.Publishing 